\title{
8 Tipps, Tricks und Erinnerungen
}

\section{Allgemein}

1. Schaltleiste dauerhaft hervorheben durch [2LMT] auf aktuelle Registerkarte

2. Es dürfen keine Umlaute, Leerzeichen oder Sonderzeichen bei der Namensvergebung von Teilen, Baugruppen, Zeichnungen etc. verwendet werden.

3. Wenn mehrere Elemente angewählt werden sollen $\rightarrow$ [STRG]

4. Mittels [RMT] kann zwischen den sich hinter dem Cursor befindlichen Teilen, Flächen gewählt werden. Hierzu den Cursor auf das Teil bewegen und durch mehrmaliges [RMT] die gewünschte Fläche vorselektieren und mit [LMT] anwählen.

\section{Skizziermodus}

1. Die Skizze muss immer Bezug zu mind. einer Ebene, Achse oder Körperkante haben. In der Skizze sollen die Maße verwendet werden, die für die spätere Zeichnung benötigt werden.

2. Es kann sinnvoll sein, zunächst eine Linie zu zeichnen, zu bemaßen und anschließend wie gewohnt weiter zu zeichnen.

3. Beim Skizzieren ist darauf zu achten, dass keine Bedingungen gleicher Länge erzeugt werden wie bspw. „L“, wenn diese nicht explizit gewünscht sind.

\section{Rotation}

1. Erst Drehachse festlegen, dann erkennt Creo die Durchmessermaße direkt

2. Die (Geometrie-)Mittellinie entspricht der Drehachse. Sie ist zwingend erforderlich und darf nur einmal je Rotations-KE vorkommen.

3. Die Kontur muss wie auch bei der Extrusion geschlossen sein. Die Konturlinie, welche sich auf der Geometrielinie befindet, wird allerdings schnell vergessen.

\section{Bohrungen}

1. Hat man eine falsche Referenz als Startfläche gewählt, so ist lediglich die gewünschte Startfläche nochmal anzuwählen.

\section{Baugruppe}

1. Die Baugruppe und deren Einzelteile müssen in demselben Verzeichnis liegen.

2. Das erste Teil einer Baugruppe immer auf Standard legen.

3. Bei Erscheinen des Zeichens $Q$ : [STRG] - A

4. Man kann in der Baugruppe die Form und Maße von Einzelteilen verändern.

\section{Zeichnung}

1. Zeichnungsdatei und zu zeichnendes Teil / Baugruppe in ein gemeinsames Verzeichnis, andernfalls kann es vorkommen, dass Creo „ein leeres Teil“ darstellt.

2. Bezeichnung der Zeichnung üblicherweise identisch mit der Bezeichnung des zu zeichnenden Teils 7 Baugruppe $\rightarrow$ Unterschied liegt in der Endung (.prt / .asm und .drw) 